\title{
STUDIES ON THE CHANGES OF GLOMERULAR PERMEABILITY IN PROTEINURIA
}

\author{
YUKIO OZAWA and MAKOTO YAMAUCHI \\ Department of Internal Medicine, School of Medicine, \\ Keio University, Tokyo, Japan
}

(Received for publication January 28, 1963)

The view is wildly held currently that renal proteinuria is primarily the results of increased permeability of glomerular capillary membrane $(1,2,3,4)$. The purpose of this paper is to study the passway of high molecular substance through the glomerular capillary membrane and the permeability of that membrane in renal diseases. This study was not so easy, because urinary protein contents, which was able to be determined by our routine work, were exceedingly modified by tubular reabsorption and we are hardly to know the true protein contents in the glomerular filtrate. For this study, we used the isolated rabbit's kidney perfusion technique and Dextran preparation in the clearance method in order to exclude the effect of tubular reabsorption.

\section{MATERIALS AND METHODS}

1) The isolated rabbit's kidney perfused with ice cold serum (=cooled kidney): Rabbits, weighing 2 to $2.5 \mathrm{~kg}$, were anesthetized by Nembutal intravenously at a dosage of $2 \mathrm{mg} / \mathrm{kg}$ body weight. Heparinization was sufficiently given. After laparotomy, additional local anesthesia was sufficiently carried out with Xylocain to get rid of nervous irritation, then left kidney was removed. Experimental procedure on perfusion of isolated kidney at $4^{\circ} \mathrm{C}$, needed ingenious technique, was shown in Fig. 1.

2) Electronmicroscopic study on the passway of high molecular substance through glomerular capillary membrane.: Imferon(3) (BENGER LABOLATORIES, HOLMES CHAPEL, CHESHIRE, ENGLAND) containing $50 \mathrm{mg}$ elemental iron per $\mathrm{ml}$ was prefered. The cooled kidney was perfused with Imferon at a dosage of $100 \mathrm{mg} / \mathrm{kg}$ body weight and the results was compared with the control which had a normal kidney and was given intravenously the same dosage of Imferon. Ten minutes after administration of Imferon, the kidneys in the rabbits, which were normal, of Masugi's nephrits, or damaged by mercurials, were removed, cut into small pieces and fixed in $1 \% \mathrm{OsO}_{4}$ solution buffered at $\mathrm{pH} 7.2$ 


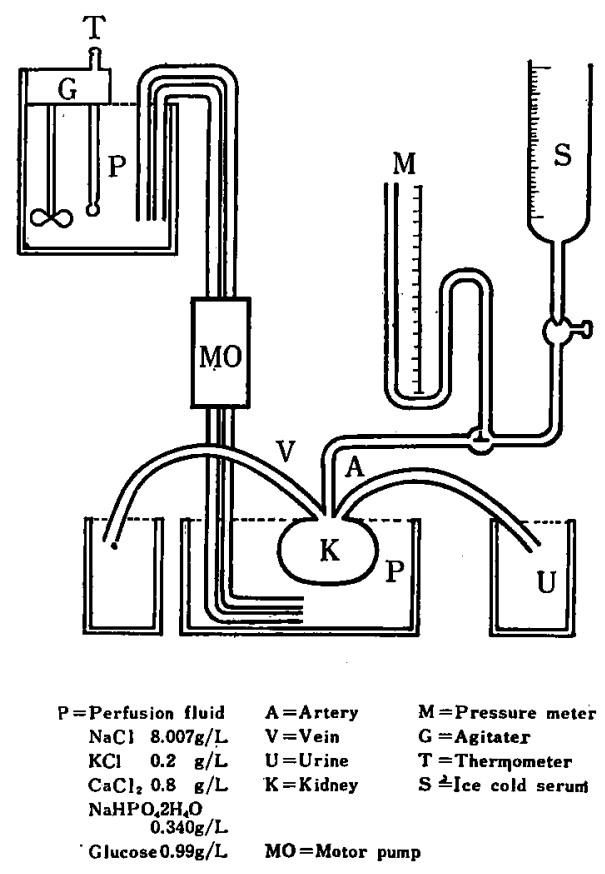

Fig. 1 Isolated kidney perfusion in the rabbit.

by veronal acetate buffer solution with $0.25 \mathrm{M}$. succarose for 2 hours, dehydrated in alcohol and embeded in 1:4 mixture of methyl and a n-butyl methacrylate, and then electronmicroscopic study was done. Details of this method with Imferon has been given elsewhere by Kawamura. ${ }^{(5)}$

3) Protein contents in glomerular filtrate.: The urinary protein derived from perfused cooled kidney at $4^{\circ} \mathrm{C}$ with ice cold serum was corrected by exogeneous creatinine $u / p$ ratio. Creatinine level in plasma and urine was determined by the Jaffe's method. The protein level in plasma and urine was determined by the method with Gornall's Biuret reagent. Urinary protein was dialised using cellophane (No. 360) tube with cooled Polyethylenglycol-veronal buffer (molecular weight $=20,000-30,000$ ). The protein in serum and urine was fractionized by paperelectrophoresis (Toyō Roshi Co., Ltd. No. 51 filter paper, 239 vol $/ 23 \mathrm{~cm}, 10$ hours) with veronal buffer of $\mathrm{pH} 8.6(\mu=0.05)$, and proteins were stained with Amido-schwartz $10 \mathrm{~B}$ solution (0.5 g of Amido-schwartz $10 \mathrm{~B}$ dye was dissolved in $100 \mathrm{ml}$ of the mixture of 9:1 ethanol: glacial acetic acid [Vol: vol]) (6). The percentage distribution of each protein fraction in serum and urine was determined by direct photometric reading after staining. A red filter $\left(660 \mathrm{~m}_{\mu}\right)$ was used for measurement. 
Table 1.

Cumulative Frequency Distribution Curve of Dextran Ethanol Turbidity

\begin{tabular}{ccc|rcc|rrr}
\hline \hline \multicolumn{3}{c|}{ Used Dextran } & \multicolumn{3}{c|}{ H.M.F. } & \multicolumn{3}{c}{ L.M.F. } \\
Series & M.W. & $\eta$ & M.W. & W.R. & $\eta$ & M.W. & W.R. & $\eta$ \\
\hline A & 71,000 & 0.24 & 238,000 & 8.3 & 0.34 & 15,000 & 6.5 & 0.11 \\
B & 50,000 & 0.20 & 118,000 & 9.4 & 0.31 & 15,000 & 7.7 & 0.11 \\
C & 32,000 & 0.16 & 71,000 & 7.5 & 0.24 & 8,800 & 9.5 & 0.08 \\
\hline
\end{tabular}

H.M.F. $=$ High molecular fraction of Dextran

L.M.F. $=$ Low molecular fraction of Dextran

M.W.= Mean morecular weight of Dextran

W.R. $=$ Weight ratio

$\eta=V$ iscosity

4) The relative Dextran clearance (=Dextran clearance in per cent of GFR) was performed with a series of Dextran preparation (Table 1). The Dextran in serum and urine was determined by Anthrone method and the estimation of its fraction in serum and urine was done by the method of ethanol turbidity which was modification of Wallenius' method(7). Beckman Model B spectrophotometer was used at $229 \mathrm{~m}_{\mu}$ (Figs. 2. 3.). Prior to the relative

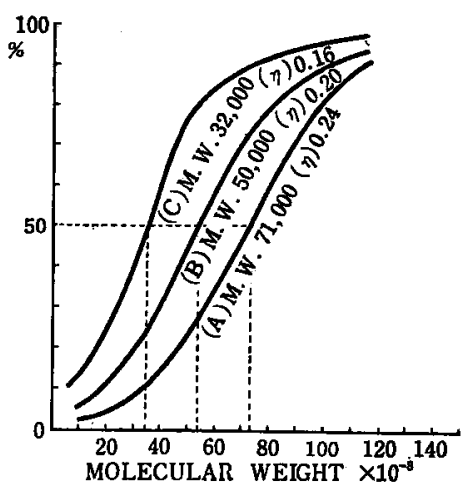

Fig. 2 Cumulative distribution curve of dextran.

Fig. 3 Histgram of dextran molecular weight induced from cumulative distribution curve.
(A)

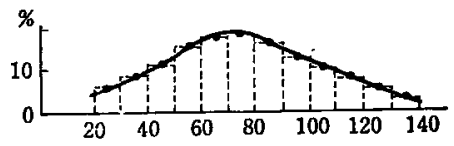

(B)

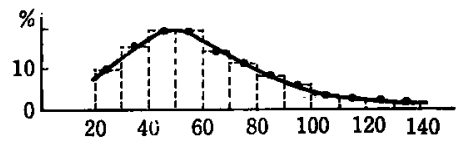

(C)

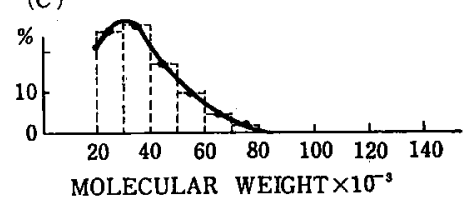

Dextran clearance test, the relative protein clearance ratio to albumin (in per cent) was determined by the methods mentioned above. The patient's hight and weight were recorded for calculation of the body surface area. The patients were reclining during the test, limited activity. One hour before the test was 
to start, the patients were given about $1,000 \mathrm{ml}$ of water. Thirty minites after drinking water, the patients were injected intravenously $200 \mathrm{ml}$ of $6 \%$ Dextran solution that was composed of $30,000,50,000$, and 70,000 mean molecular weight Dextran preparation. Then 30 minutes after the completion of Dextran injection, the patients had empty their bladder. Discarded this urine. Recorded the exact minutes the bladder was empty. Ten to $15 \mathrm{ml}$ of blood was drown as soon as their bladder was empty. Noted the time exactly. Collected all excreted urine for 30 minutes after the initial emptying of the bladder, then immediately, the same amounts of blood was drown. The plasma and urine specimens were analysed by the above mentioned methods. For this study, we chose 3 healthy men and 19 patients: acute glomerulonephritis 2 , chronic glomerulonephritis 5 , chronic renal insufficiency 2, nephrosclelosis 2, nephrotic syndrome 2, Kimmelstiel-Wilson's syndrome 2, disseminated lupus erythematosus 2, pregnancytoxemia 1, and orthostatic albuminuria 1.

\section{RESULTS AND DISCUSSION}

1) The study of passway for high molecular substances (Protein and Dextran) :

In the past, men have to tried to discuss glomerular permeability mainly by calculating the diameters of small openings, which were supposed to exist or could be seen by electronmicroscopy (Hall) (8) in the basement membrane and its inner and outer layers, endothelium and epithelium of the glomerular capillary wall. And high molecular substances which passed through glomerular capillary membrane were supposed to penetrate through only small openings by passive transport, as shown in Fig. $4 \mathrm{~A}$. In 1960 Farquhar et al ${ }^{(9,10)}$ gave us clues to analyse

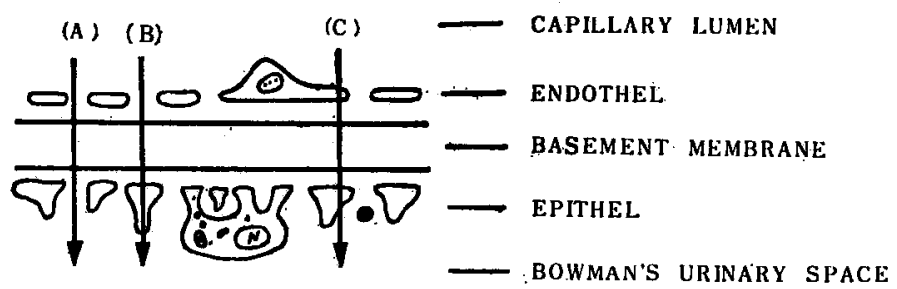

Fig. 4 Passway of the substances through the glomerular capillary membrane.

the passway of high molecular substances in penetrating the glomerular capillary wall with aid of ferritin. In their study, the proteins were segregated into droplets by the epithelium of glomerular capillary. Oshima et al also described the same results( ${ }^{(4)}$. Kawamura made some observations regarding the similar 
passway of high molecular substances with aid of Imferon(5). These results showed the possibility that the passway of high molecular substances was not only through the small opening as shown in Fig. $4 \mathrm{~A}$, but through the intracellular passway as shown in Fig. 4 B, C. However, when electronmicroscopic findings by Farqhar were compared with those of Kawamura, pinocytosis and phagocytosis that suggested active transport were more frequently found in the case with ferritin than in the case with Imferon. These differences suggested us the possibility that the protein particles were incorporated into cells, and they were destructed in cells, or passed through the cells by means of other transport. Suppose suppressed the exergy metabolism in the cooled kidney, the suppressed activity of cells, both endothelial and epithelial, should have inactivated incorporation of Imferon by the way of active transport. However, no difference was found in Imferon incorporation into both endothelial cell and epithelial cell at glomerular capillary membrane between the cooled kidney that perfused with Imferon (Plate, Fig. 5A) and the control that given Imferon intravenously (Plate, Fig. 5B). The same results were obtained in both Masugi's nephritis and mercurial damaged kidney. From these findings, the authors considered that the incorporation of Imferon into the cell was not only by the active transport but the passive transport. However the incorporation of both ferritin and Imferon into cells was not found without administration of large quantity of these substance. Without administration of these substances in the normal kidney, electronmicroscopic findings such as pinocytosis and phagocytosis seen in the case of ferritin administration, could not be found. Consequently, it might be the main route of transport that protein penetrate through small openings at glomerular capillary membrane as shown Fig. $4 \mathrm{~A}$, and the very small amount of proteins incorporated into cells might be mostly destructed in the cells.

2) Experimental study of glomerular permeability by the cooled kidney perfusion in the rabbits.:

A) Effect of the both pressure and proteinconcentration on perfusion.: Cooled kidney became swollen and congestive when the perfusionpressure reached at a level of $80 \mathrm{mmHg}$, which was as high as renal arterial pressure in anethetized normal rabbit. When Dextran preparation was administered on the same procedure, high molecular fraction, over 100,000 of molecular weight, was discharged into urine. In normal rabbit administered various molecular weight Dextran fraction, Dextran fraction, over 100,000 of molecular weight, was not discharged into urine. In that condition, the renal blood pressure was thought to be $80 \mathrm{mmHg}$. In order to inhibit the urinary excretion of high molecular Dextran fraction, the perfusionpressure in cooled kidney must be decreased to a level of $40 \mathrm{mmHg}$. 
Above mentioned functional difference between perfusionkidney and normal kidney was due to disturbances of renal hemodynamic mechanism which were regulated by nervous and other controls, but details were yet unknown. When the perfusionpressure increased from 40 to $80 \mathrm{mmHg}$ at a fixed concentration of perfused human serum albumin, the protein contents in glomerular filtrate rose up to a level about $2 \frac{1}{2}$ times much as shown in Fig. $6 \mathrm{~A}$. And the protein

A

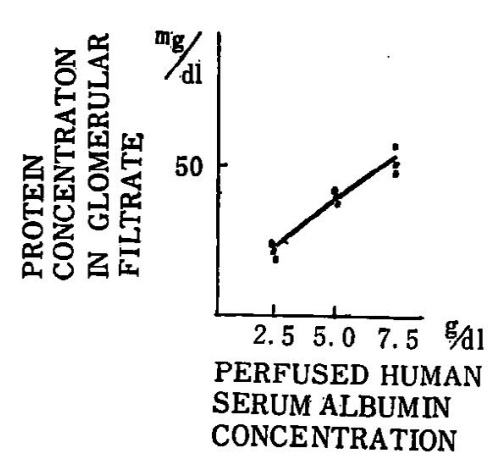

B

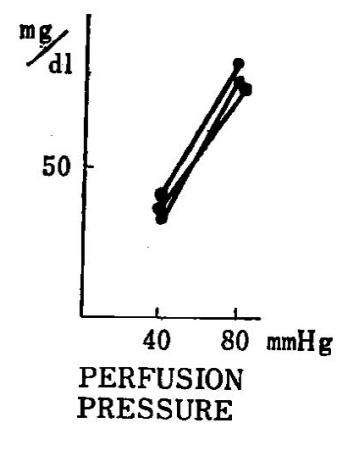

Fig. 6 Glomerular protein concentration related to perfused human serum albumin concentration (A) and perfusionpressure (B).

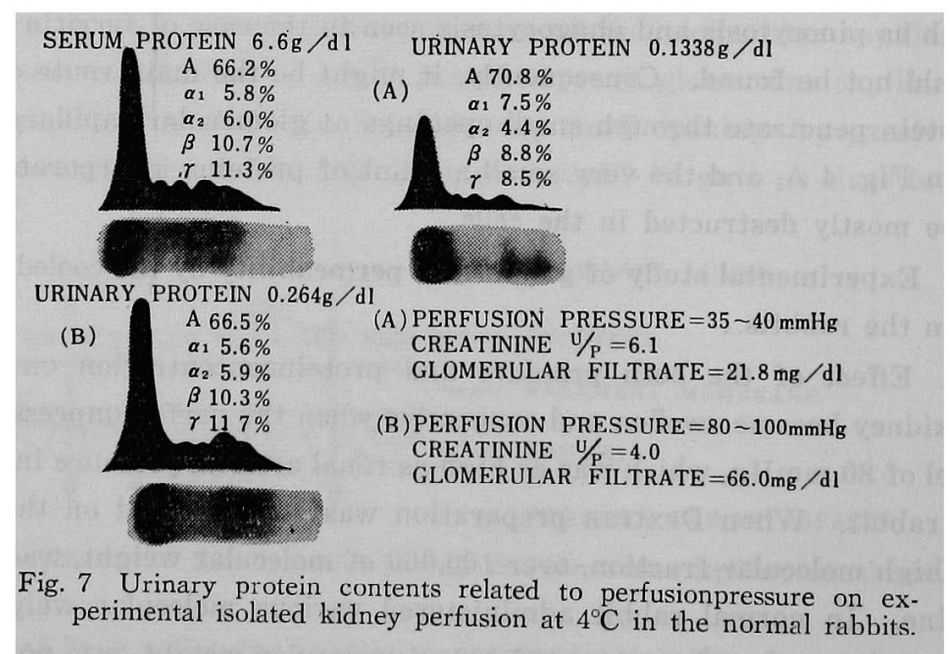

pattern in it became similar to that of serum (Fig. 7). It was obviously appeared that the glomerular permeability of protein was increased with the elevation of either perfusion-pressure or arterial pressure. These factors seem to play an 
important part on pathogenesis of proteinuria in hypertension or congestive kidney. However, in the experimental cooled kidney, it is not obvious that the accelerated glomerular permeability was mainly due to whether elevated intracapillary pressure or glomerular capillary distension. When the perfusionpressure was fixed at a level of $40 \mathrm{mmHg}$, the protein contents in glomerular filtrate derived from the cooled kidney showed straight linear relation with perfused human serum albumin concentration.

B) Protein concentration and its fraction in glomerular filtrate.: Originally, Wearn and Richard(11) demonstrated that the glomerular filtrate in normal frog contained less than $1 \%$ of protein compared with serum protein concentration by micropuncture. On the same procedure, Walker(12) revealed the fact that glomerular filtrate in mammals, rats and guineapigs, contained a trifle protein. Dock (13) demonstrated that the urinary protein contents became similar to those of glomerular filtrate by isolated rabbit kidney perfusion with ice cold serum and the protein concentration in urine was about $15-22 \mathrm{mg} / \mathrm{dl}$. Summing up those results add to that of Bott(14), Bradley(15), and Oliver(16), the protein concentration of glomerular filtrate was supposed to be less than $25-35 \mathrm{mg} / \mathrm{dl}$. However, the protein fraction in it was still yet unknown. In our procedure, protein contents, corrected by creatinine $u / p$ ratio, which was assumed as that of glomerular filtrate, contained the mean level of $25.9 \mathrm{mg} / \mathrm{dl}$ in 4 normal cases (Table 2). And

Table 2.

Glomerular Filtrate Protein Concentration during Isolated Rabbit's Kidney Perfusion with Ice Cold Serum in Anesthetized Normal Rabbits

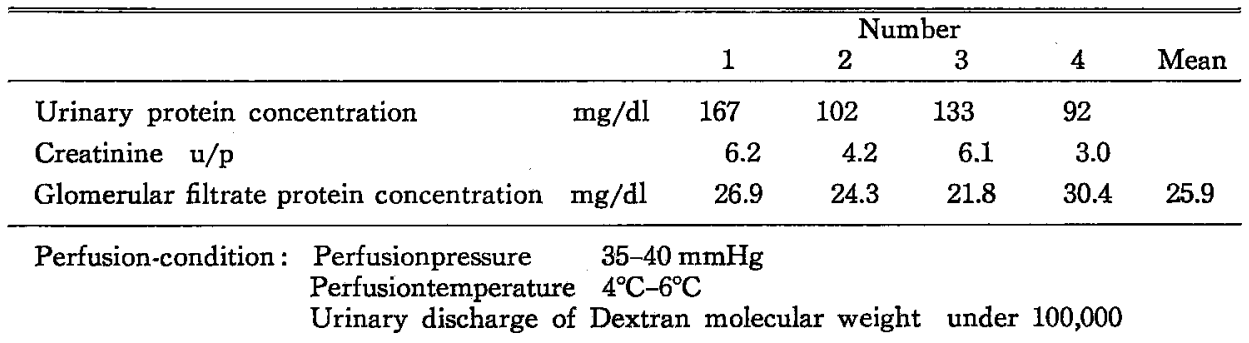

protein pattern was characterized by a large amount of albumin and a small amount of globulin fraction compared with serum protein (Fig. $8 \mathrm{~A}$ ). In these cases, it was assumed by electronmicroscopy that the glomerular capillary membrane after perfusion was not injured. Each protein fraction clearance value was almost inversely proportional to their molecular weight, with some exceptions. Protein contents in glomerular filtrate reached $2,200 \mathrm{mg} / \mathrm{day}$, calculating from assumption that the protein contents was $26 \mathrm{mg} / \mathrm{dl}$ and $\mathrm{GFR}$ was $6 \mathrm{ml} / \mathrm{minute}$ in normal rabbit. In contrast, protein contents in urinary bladder (Fig. $8 \mathrm{~B}$ ), 
characterized by a large amount of globulin and a small amount of albumin, compared with that of glomerular filtrate (Fig. $8 \mathrm{~A}$ ), suggesting that the tubular reabsorptive protein fraction was mostly albumin. Considering from human urinary protein fraction which was similar to that of rabbit, the same process was supposed to be done in normal human beings. By the same experimental procedure, the protein fraction in glomerular filtrate in both Masugi's nephritis and mercurials damaged kidney was characterized by much globulin fraction, which suggested that there were increased permeability of glomerular capillary membrane, and increased protein contents (Fig. 9). It is evident that proteinuria was

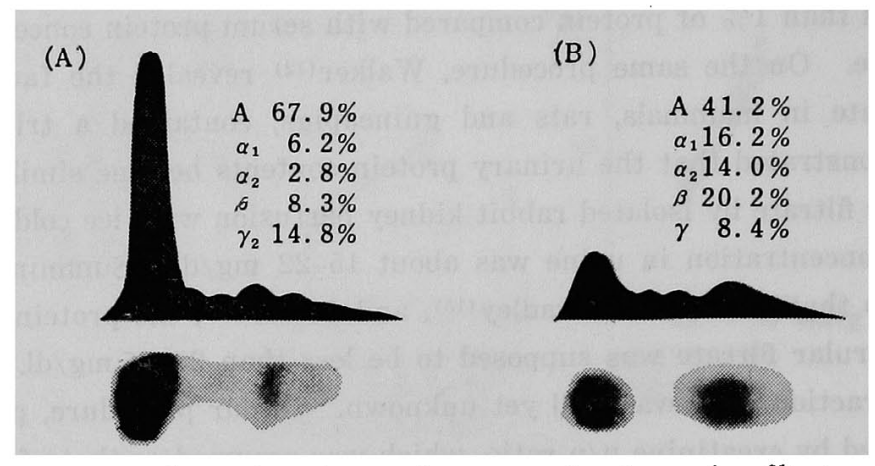

Fig. 8 Electrophoretic protein pattern in glomerular filtrate during expermental perfusion (A) and that of bladder urine (B) in normal rabbit.

$\begin{array}{lll}\text { NORMAL } & \text { MERCURIAL } & \text { MASUGI'S } \\ & \text { DAMAGED } & \text { NEPHRITIS } \\ & \text { KIDNEY } & \end{array}$
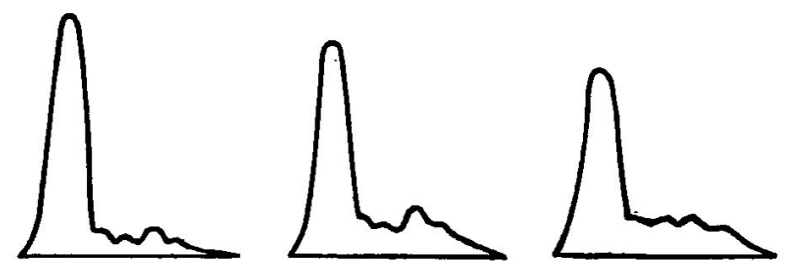

Fig. 9 Paperelectrophoretic protein pattern in glomerular filtrate of rabbits, conditioned by normal, mercurials damaged kidney, and Masugi's nephritis.

induced from accelerated glomerular permeability. Previously, proteinuria in mercurials damaged kidney was due to declined tubular reabsorption, not to damagd glomerular capillary membrane. However, Sakaguchi and Kawamura(17) demonstrated the damaged glomerular capillary membrane in mercurials damaged rabbit's kidney by electronmicroscopy. From our experimental results in mercurials damaged kidney, there were increased urinary globulin concentration, 
urinary discharge of more than 100,000 molecular weight Dextran fraction, and prominent increased protein concentration in glomerular filtrate, and those findings showed the accelerated glomerular permeability.

3) Glomerular permeability by means of Dextran preparation.:

A) Evaluation of relative Dextran clearance in per cent of GFR.: Relative Dextran clearance curve composed of clearance values of several different molecular weight fraction showed that relative Dextran clearance of low molecular fraction (mean molecular weight-8,000) had much higher value than GFR (Fig. $10 \mathrm{~A}$ ). This contradiction seemed to be resulted from estimation error. So we corrected clearance value of low molecular Dextran in order to coincide with GFR,
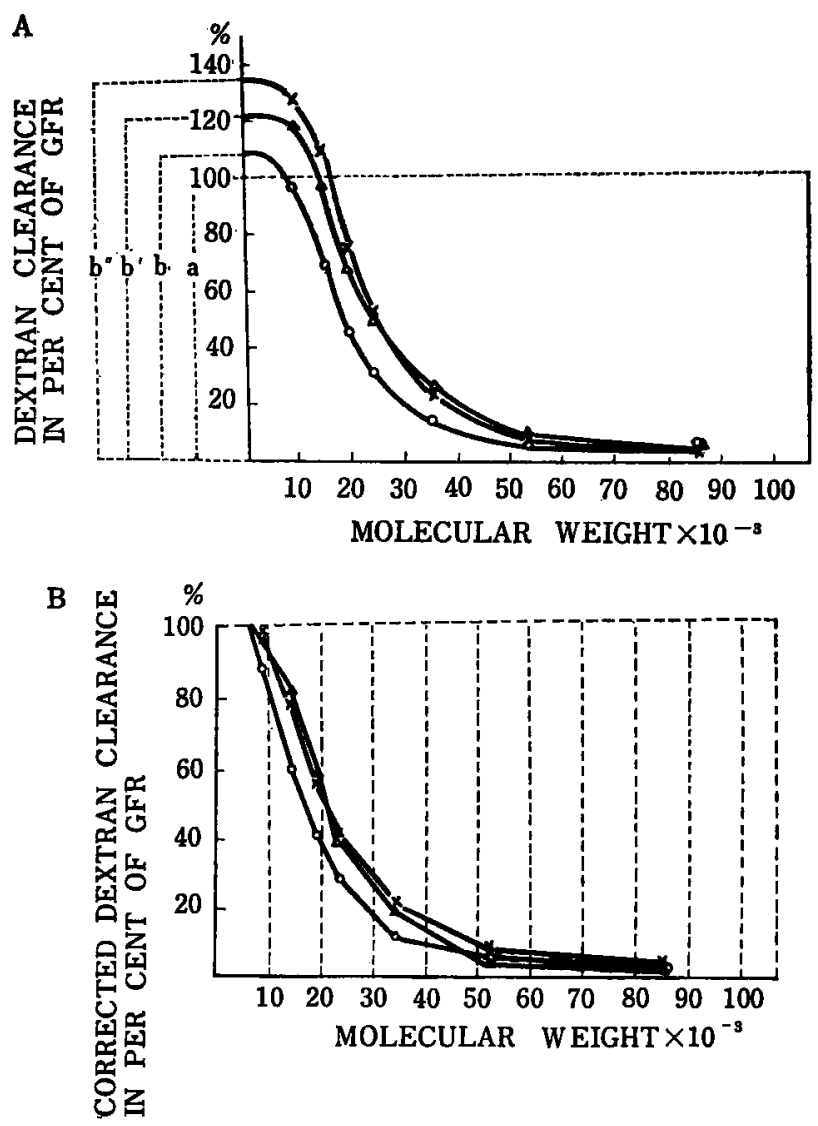

Fig. $10 \mathrm{~A}$ The renal clearance of Dextarn in per cent of glomerular filtration rate and its relation to molecular weight of Dextran, in 3 healthy subjects.

B The corrected renal clearance of Dextran in per cent of glomerular filtration rate and its relation to molecular weight of Dextran, in 3 healthy subjects. 
as shown by the a/b ration in Fig. $10 \mathrm{~A}$. In healthy subjects, over 100,000 molecular weight Dextran clearance value was equal to zero without discharging into urine.

B) Glomerular permeability from the standpoint of relative Dextran clearance.: Assumed that the filtration ratio of low molecular substances which were freely passed through the glomerular membrane was 100, relative Dextran clearance curve showed filtration ratio of each molecular weight (Fig. 10 B). As higher Dextran molecular weight became, filtration ration was remarkably decreased. The changing permeability could be considered using this curve. At first, we assumed that there were pores in the glomerular membrane which had regular effective radius and that changes of effective radius in it indicated the permeability. By the use of Pappenheimer's formula(18), mean effective radius of the pores in healthy subjects was calculated to be $50 \AA$ ranged from $47 \AA$ to $53 \AA$. The distribution of them was supposed to be similar to that of Gaus, because glomerular permeable membrane was biological membrane. From relative Dextran clearance curve, $50 \%$ of GFR indicated 20,000 molecular weight. These re-

\begin{tabular}{ll|l|l|r}
\hline E. R. & M. W. & E. R. & M. W. \\
\hline 4 & $0 \AA$ & 10,200 & $70 \AA$ & 54,400 \\
$45 \AA$ & 14,200 & $75 \AA$ & 66,900 \\
5 & $0 \AA$ & 20,000 & $80 \AA$ & 81,200 \\
55 & 8 & 26,400 & $85 \AA$ & 97,400 \\
60 & $0 \AA$ & 34,300 & $90 \AA$ & 115,800 \\
$65 \AA$ & 43,500 & $95 \AA$ & 136,000
\end{tabular}

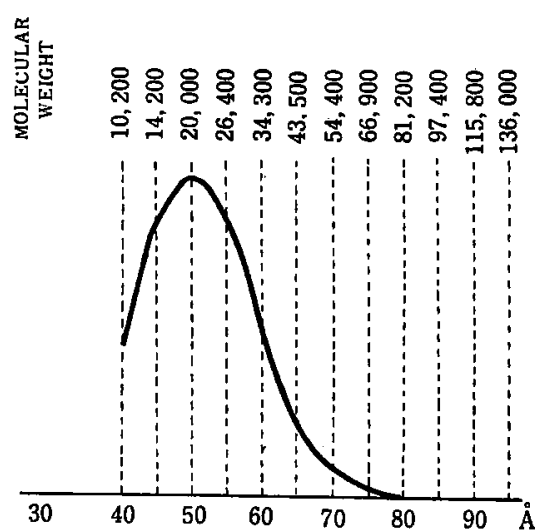

EFFECTIVE RADIUS OF THE PORES

Fig. 11 Dextran molecular weight related to effective radius of supposed pores in the glomerular capillary membrane.

E.R. $=$ Effective radius of supposed pores in the glomerular capirary membrane.

M.W.=Mean molecular weight of Dextran.

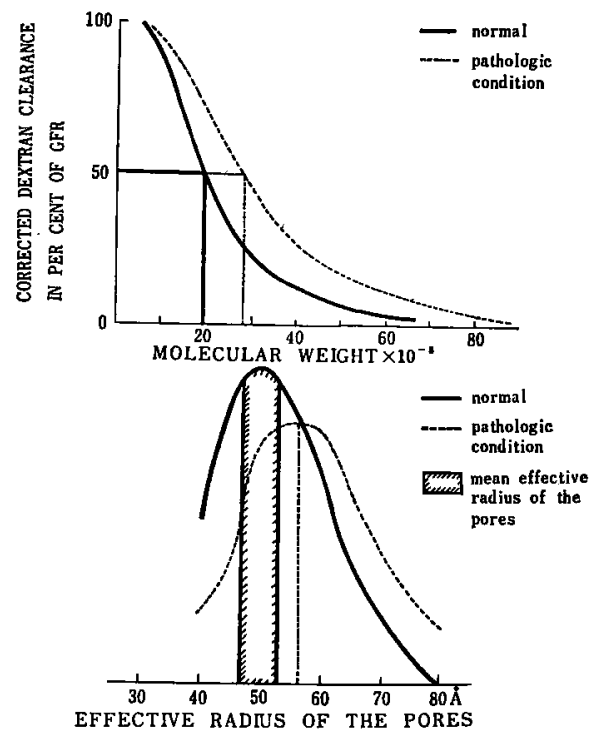

DISTRIBUTION CURVE OF PERMEABLLTTY

Fig. 12 Conversion from corrected relative Dextran clearance curve to distribution curve of permeability by means of histgram. 
sults were thought to indicate that 20,000 molecular weight Dextran possibly pass through the pores which was half of all pores in glomerular capillary membrane. In addition, effective radius of the pores was assumed to be paralleled to a cube root of the molecular weight. For example, as shown in Fig. 11, 66,900 of molecular weight ranked with $75 \AA$ of the pore. On the premise of this assumption, the relative Dextran clearance curve was chosen as a cumulative frequency distribution curve of permeability by means of histgram (Fig. 12). According to this method, we found similar distribution curve to that of Gaus in normal persons. And maximum effective radius of pores reached to about $80 \AA-85 \AA$. The dotted line in Fig. 12 showed accelerated permeability, as the curve was migrated to the larger pores. The mean effective radius of pores was induced from the value which ranked at $50 \%$ of GFR, without using Pappenheimer's formula.

4) Clinical observations in renal diseases by Dextran clearance.: The area which was included by distribution curve was designed to be proportional to GFR vaiue of each case and the standard GFR value, namely $110 \mathrm{ml} / \mathrm{minute} / 1.48 \mathrm{~m}^{2}$. As shown in Fig. 13, the distribution curve in diseased state was not resemble that of Gaus. Therefore, the mean effective radius of pores by our method was also not so exact that was calculated from Pappenheimer's formula. It is impossible to ask for the exact mean value without obtaining the complete distribution curve. However we can not get the value of under 10,000 molecular weight Dextran. Until the more exact method is available, we should be inclined to adopt our method. In Fig. 13, right upward curve in each figure represents relative protein clearance ratio to albumin (in per cent).

Acute glomerulonephritis (Fig. 13. No. 1, 2.) :-The mean effective radius of pores in 2 cases were $53.5 \AA$ and $53.0 \AA$ that represented the upper limits of normal range. These results did not show accelerated permeability though some deviation toward larger radius was observed in the distribution curve. When we regarded the distribution curve as nephronpopulation concerning glomerular permeability, this change in distribution curve was meant that whole glomerular permeability was uniformaly increased. And a trifle of over 100,000 molecular weight was discharged into urine. These results suggested possible acceleration of permeability in the only small number of glomeruli, while the increased permeability were scarcely found in the majority of glomeruli. The authors also considered that blood cells were not leaked out through these glomeruli with accelerated permeability but leaked out through a small number of destructed glomeruli. Schematically, right deviation of distribution curve was delineated to extend for larger radius.

Chronic glomerulonephritis:-(a) The case with renal dysfunction (Fig. 13. 

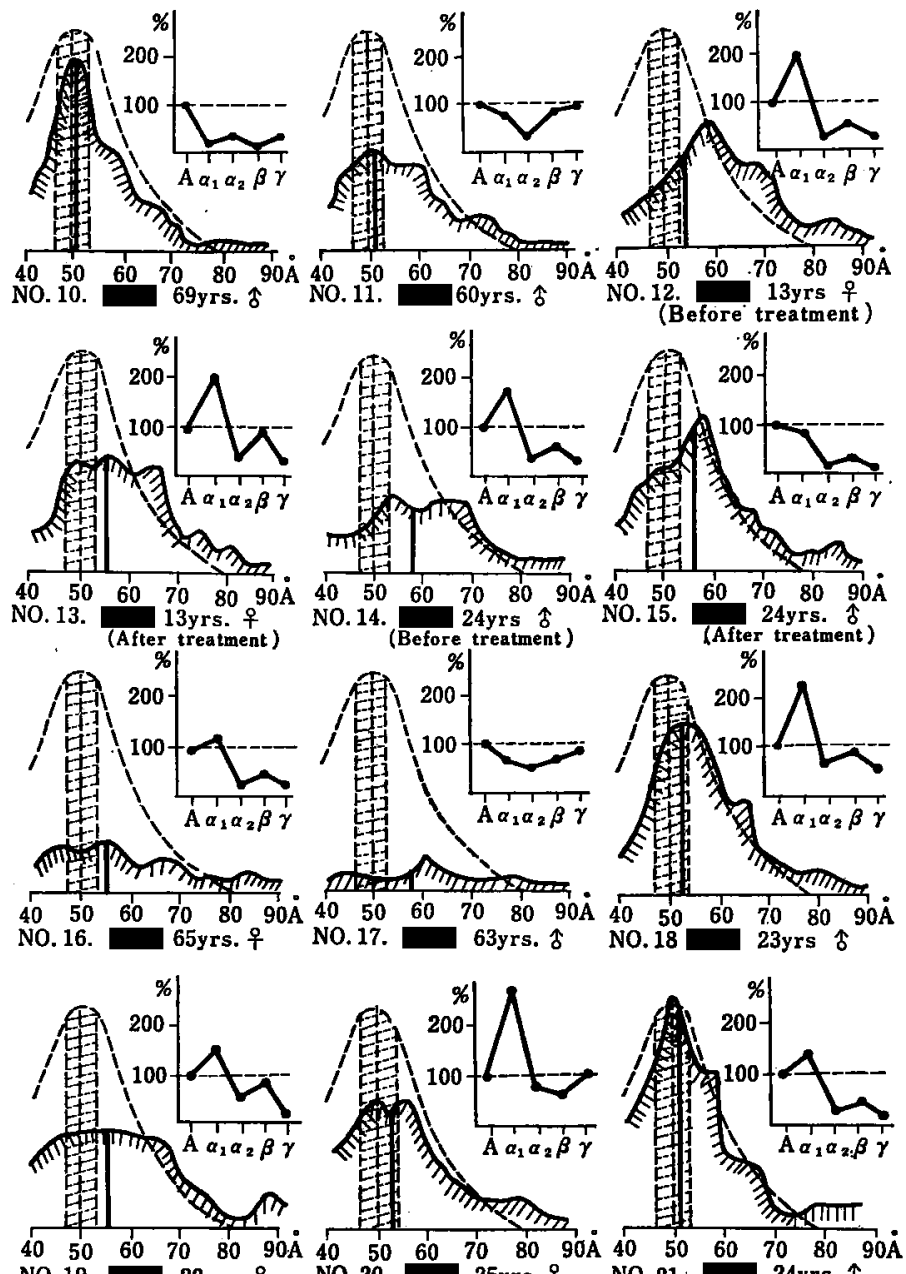

NO. 19 .

40
NO. 20

No. 21 .

presupposing nephritis edema, oliguria, and tiredness. Renal biopsy revealed chronic glomerulonephritis in progress degree. In renal function test, GFR was decreased to $38.7 \mathrm{ml} /$ minute $/ 1.48 \mathrm{~m}^{2}$ with moderate azotemia. In contrast, much albumin fraction was excreted in the urine and much over 100,000 molecular weight Dextran was discharged into urine. This case showed that distribution curve was not necessarily proportional to relative protein clearance. (c) The case with severe renal dysfunction, such as renal insufficiency (Fig. 13. No. 8,9). Mean effective radius of pores were over normal limits $(56.0 \AA, 63.0 \AA)$. The type of distribution curve was deformed to flat, prominently extended for larger radius. Urinary globulin contents and their clearance value were increased. These results 

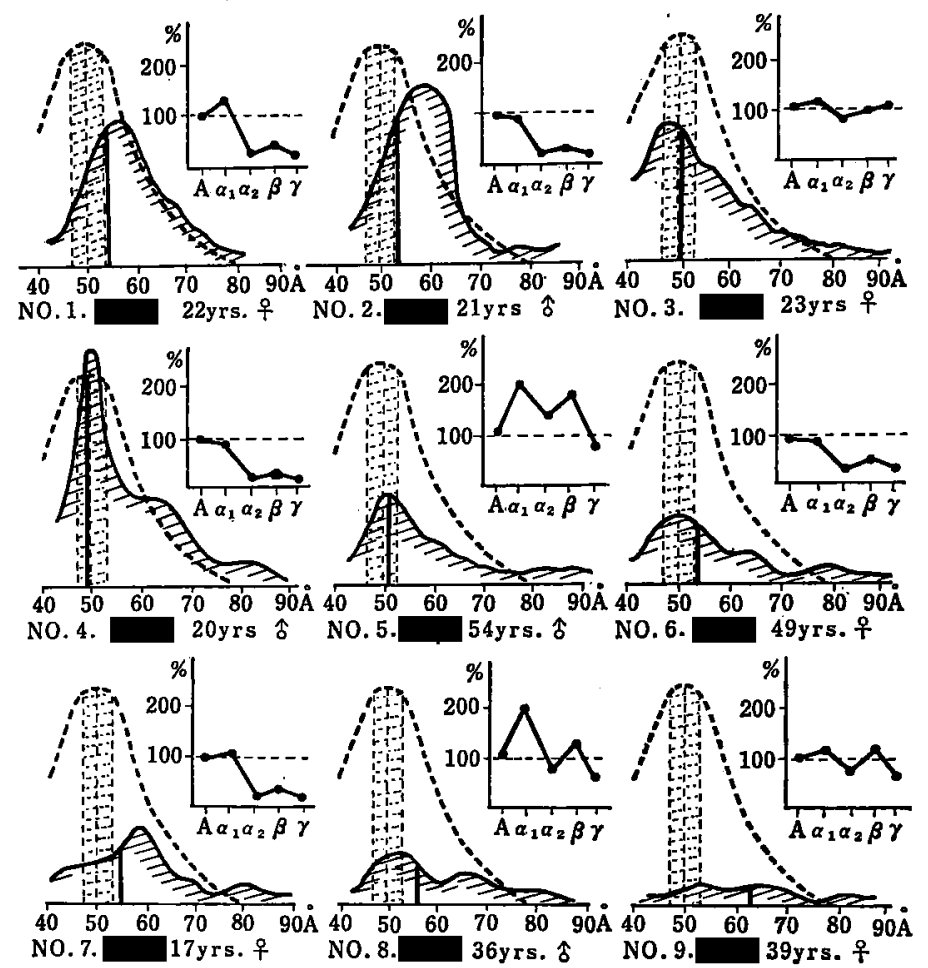

Fig. 13 Each figure showes distribution curve of effective radius of pores in glomerular membrane:

Dottedline-normal distribution curve and its mean effective radius. Its normal range.

Solid line-that in diseased states

No. 3, 4.). The mean effective radius of pores were within normal limits (51.8 $\AA$, $49.0 \AA$ ). The type of distribution curve was declined to be sloped slightly to the larger radius than that in the case of acute glomerulonephritis. These results suggested that the glomeruli with accelerated permeability were increased in number. (b) The case with moderate renal dysfunction (Fig. 13. No. 5, 6, 7.). The mean effective radius of pores were upper limits of normal $(52.0 \AA, 54.0 \AA$ and $54.0 \AA$ ). The type distribution curve yield to slope more loosely for larger radius, created both concave and convex. In these cases, the much globulin fraction was excreted in the urine with elevation of globulin relative clearance in each fraction. Dextran fraction, over 100,000 molecular weight, was increasingly excreated in the urine on the clearance test. These results implied that the glomeruli with relatively increased permeability were gradually appeared with the progress of irregular glomerular injury. Sixteen year-old female, the case No. 7, was admitted with sudden retinal bleeding, hypertension, and hematoproteinuria with 
indicated the destruction of glomeruli and prominent increased permeability.

Nephrosclerosis:-(Fig. 13. No. 10, 11.). Mean effective radius of pores were within normal limits. $(50.0 \AA, 52.0 \AA)$. On the curve in nephrosclerosis, the one was almost the same as case of acute nephritis, the other was similar to the moderate degree of chronic nephritis. From the only 2 cases of nephrosclerosis, the authors dare say that nephrosclerosis contained many types and degrees.

Nephrotic syndrom:-(Fig. 13. No. 12, 14.). We observed 2 cases of nephrotic syndrom from effect of treatment for 2 weeks. The one was treated with ACTH (No. 12, 13.), the other was treated with steroid (betamethasone) (No. 14, 15.). Although it has been reported $(19,20)$ that the mean effective radius of pores was almost within normal limits in nephrotic syndrom, it was enlarged in our results (57.0 $\AA$, 55.5 $\AA, 57.0 \AA$ and $55.0 \AA$ ). The curve was hill-form, which meant increased permeability in both high and low molecular fraction. In the ACTH therapy case, urinary protein concentration decreased (No. 13). In the steroid therapy case, urinary protein concentration and edema were dramaticaly improved. After effective treatment of them, the mean effective radius of pores was not improved. However, in the markedly improved case by administration of betamethasone, the curve became to slope keenly for larger radius. This result suggested improved permeability by the treatment. In addition, $\alpha_{1^{-}}$globulin clearance value was decreased.

Kimmelstiel-Wilson's syndrom:-(Fig. 13. No. 16, 17.). Mean effective radius of the pores were over normal limits (53.5 $\AA$, 57.0 $\AA$ ). The both distribution curves showed renal insufficiency type.

Disseminated lupus erythematosus:-(Fig. 13. No. 18, 19.). Mean effective radius of pores was slightly over normal limits $(54.0 \AA, 54.5 \AA)$. The one curve was nephritic type, the other was nephrotic type, despite of slight proteinuria.

Pregnanch-toxemia:-(Fig. 13. No. 20.). Mean effective radius of pores was within normal limits (53.0 $\AA$ ). The curve was resemble to nephrotic type with slight migration for larger radius with increased globulin clearance value.

Orthostatic albuminuria:-(Fig. 13. No. 21.). Mean effective radius of pores was within normal limits $(51.5 \AA)$. The curve was almost normal with slight extesnion toward larger radius. The over 100,000 molecular weight Dextran was discharged slightly into urine.

Summing up those results mentioned above, distribution curve in varius renal diseases was classified as main three types. The first was nephritic type. Slight migration for larger radius meant that the some parts of glomeruli were variably increased relative permeability. The second was nephrotic type. This type was hill-form with prominent migration toward larger radius, and sloped loosely 


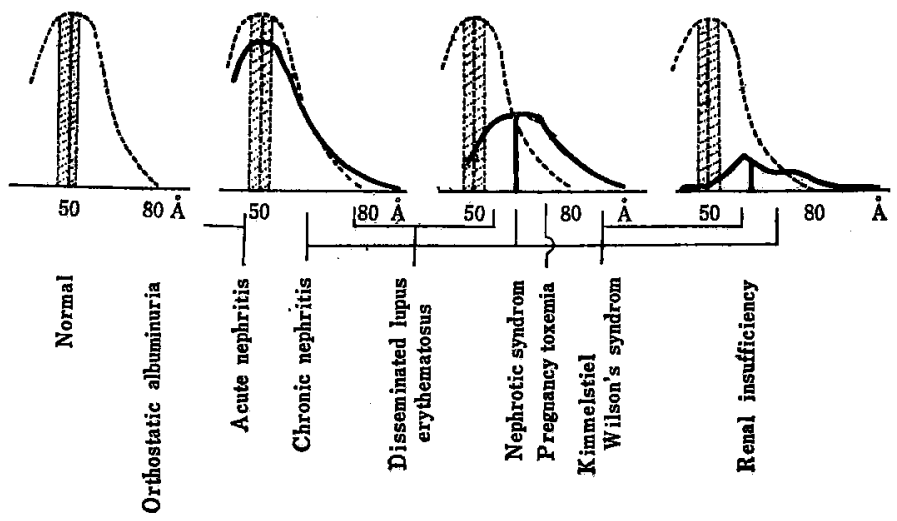

Fig. 14 Type of distribution curve in various renal disease, indicated glomerular permeability.

to larger radius, suggested increased permeability in both high and low molecular fraction. The third was renal insufficiency type. This was prominently deformed to flat with severe extension for larger radius.

\section{SUMMARY}

For the purpose to study the passway of high molecular substances through glomerular capillary membrane and the permeability of that membrane in renal diseases, we used the isolated rabbit's kidney perfusion technique at $4^{\circ} \mathrm{C}$ (=cooled kidney) and Dextran preparation in the clearance method in order to inhibit the tubular reabsorption.

(1) The incorporation of Imferon (Iron Dextran complex) into glomerular capillary cells in the rabbit, conditioned by normal, Masugi's nephritis, and mercurials damaged, was identical between the cooled kidney case and the control by electronmicrosocpy. Transport of high molecular substance, protein or Dextran, passed through cells in glomerular capillary membrane, is considered to be made not only actively but passively.

(2) Urinary protein contents derived from isolated rabbit's kidney perfused with ice cold serum was supposed to resemble to that of glomerular filtrate. The protein concentration of glomerular filtrate was increased with the elevation of pressure and protein concentration on perfusion. The glomerular filtrate protein concentration was $25.9 \mathrm{mg} / \mathrm{dl}$ in normal cases' average. After this procedure, kidney without injuring of glomerular capillary membrane was assured electronmicroscopically. Their fraction had much albumin, less globulin than that of serum. In pathologic states conditioned by mercurial injury and Masugi's nephritis, the glomerular filtrate contained increased protein concentration with 
increased globulin, and these results suggested increased permeability.

(3) The type of distribution curve which represented glomerular permeability in various renal diseases was devided to three main type. This curve indicated permeability more appropriately than mean effective radius. In addition to this results, there should be injury of glomerular capillary membrane, Dextran fraction, over 100,000 molecular weight, was excreted in urine.

\section{ACKNOWLEDGEMENT}

The authors are indebted to Prof. Toyozo Aizawa, M. D. and Assist. Prof. Seiichi Asano, M.D. for their suggestion and encouragement. Electronmicroscopic findings were though the coutesy of Assist. Prof. Hiroshi Sakaguchi, M.D. and Sadao Kawamura, M.D. in Department of Pathology, School of Medicine, Keio University. This study was presented to the Japanese Society of Nephrology in October 1962. Thanks are due to Waksman Foundation in Japan for financial support.

\section{REFERENCES}

1. Gregoire, F. et al: Am. J. Med. 25: 516, 1958.

2. Smith, H. W.: Principle of Renal Physiology, Oxford Univ. Press, New York, p. 82, 1956.

3. Oshima, K. et al: Saishin Igaku $14: 193,1959$. (in Japanese).

4. Oshima, K., and Hatano, M.: Jap. J. Nephr. 2: 295, 1960. (in Japanese).

5. Kawamura, S.: Keio J. Med., 10: 109, 1961.

6. Kobayashi, M. and Murai, K.: Roshieido no Jissai, p. 115, Nankodo, Tokyo, Japan. (in Japanese).

7. Wallenius, G.: Acta Soc. Med. Upsaliencis, 59: Suppl. 4, 1, 1954.

8. Hall, r. V.: Proc. 6th Ann. Conf. on the Nephrotic Syndrome, 1955.

9. Farquhar, M. G., and Palade, G. E.: J. Biophysic. Biochem. Cytol. 7: 296, 1960.

10. Farquhar, M. G., Wissig, S. L. and Palade, G. E.: J. Exp. Med., 113: 47, 1961.

11. Wearn, J. T. and Richard, A. N.: Am. J. Physiol., 71: 209, 1924.

12. Walker, A. M. et al: Am. Physiol. 134: 580, 1941.

13. Dock, W.: New England J. Med. 227: 633, 1942.

14. Bott, P. A. and Richard, A. N.: J. Biol. Chem. 141: 291, 1941.

15. Bradley, S. E., and Jyson, C. J.: New England J. Med. 238: 223, 1948.

16. Oliver, J.: Harvey Lectures, series 40, 102, 1944-1945.

17. Sakaguchi, H. and Kawamura, S.: Presented to the Japanese Society of Nephrology in October 1962.

18. Pappenheimer, J. R.: Klin. Wochshr. 33: 362, 1955.

19. Jahnke, K. et al: Zschr. f. Ges. Exp. Med. 131: 567, 1959.

20. Furuyama, T.: Jap. J. Nephr. 3: 431, 1961 (in Japanese). 
PLATE

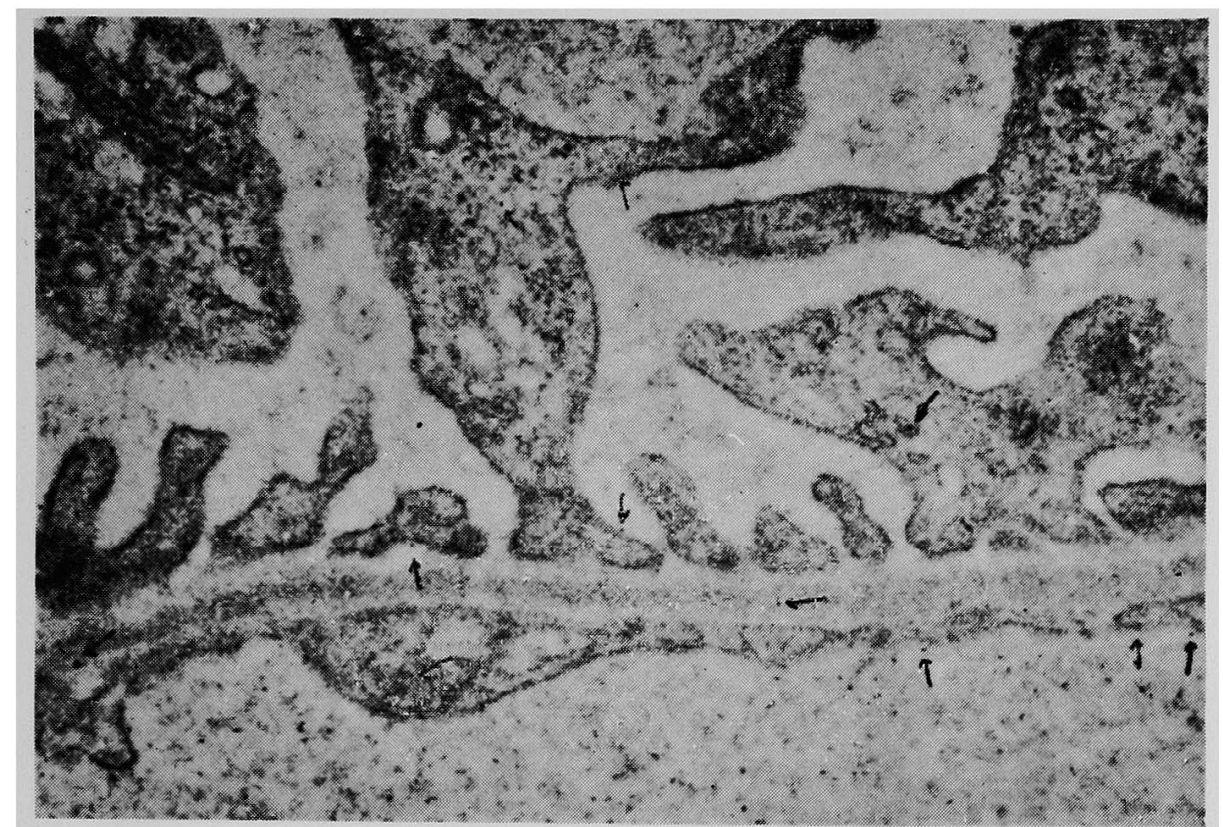

A

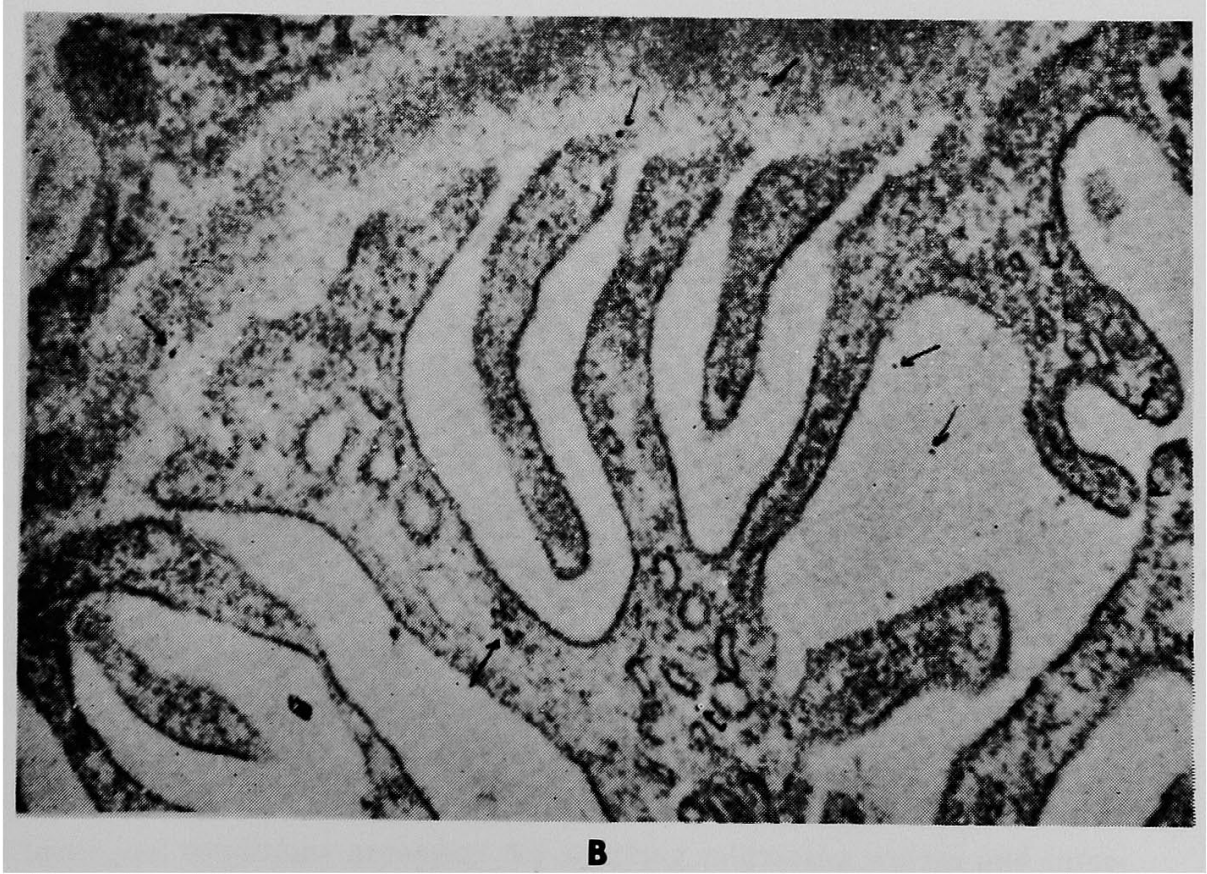

Fig. 5 Electronmicroscopic finding showes passway of $1 \mathrm{~m}$. feron throught glomerular capillary membrane.

(A) The isolated kidney perfusion with Imferon solution at $4^{\circ} \mathrm{C}$.

(B) Control which was given Imferon intravenously. Arrow in the figure showes iron particle.

Y.OZAWA and M.YAMAUCHI 